
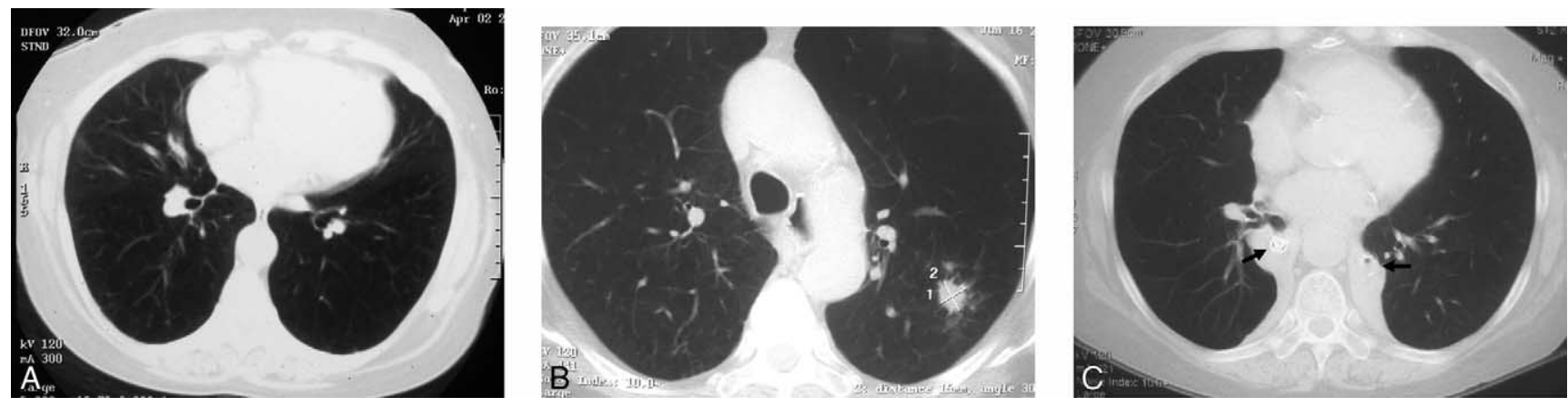

Figure 1. A, High-resolution chest computed tomography (CT) of the lower lobes before endobronchial valve (EBV) placement. B, High-resolution chest CT showing the nodule located in the posterior segment of the left upper lobe. C, Bilateral lower lobe collapse after EBV placement, and EBVs in the lower lobe bronchus, bilaterally (arrows).

2. Ost D, Fein AM, Feinsilver SH. The solitary pulmonary nodule. $N$ Engl J Med. 2003;348:2535-42.

3. Littman AJ, Thornquist MD, White E, et al. Prior lung disease and risk of lung cancer in a large prospective study. Cancer Causes Control. 2004;15:819-27.
4. Swensen SJ, Viggiano RW, Midthun DE, et al. Lung nodule enhancement at CT: multicenter study. Radiology. 2000;214:73-80.

5. Matsuoka S, Kurihara Y, Yagihashi K, Niimi H, Nakajima Y. Peripheral solitary pulmonary nodule: CT findings in patients with pulmonary emphysema. Radiology. 2005;235:266-73.

\title{
Internal thoracic vein aneurysm presenting as an anterior mediastinal mass
}

G. Hossein Almassi, MD, Milwaukee, Wis

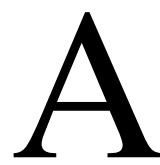

nterior mediastinal masses most commonly are associated with thymic, thyroid, parathyroid, and lymphatic origin. Excluding aortic disease, vascular origin for anterior mediastinal masses is not common. We present a case of an aneurysm of the internal thoracic vein presenting as an enlarging anterior mediastinal mass.

\section{Clinical Summary}

A 52-year-old woman underwent a triple arthrodesis of the right foot for orthopedic injuries sustained in a car crash 16 months

\footnotetext{
From the Division of Cardiothoracic Surgery, Medical College of Wisconsin, Milwaukee Wis.

Received for publication July 7, 2005; revisions received Sept 21, 2005; accepted for publication Sept 28, 2005.

Address for reprints: G. Hossein Almassi, MD, Professor, Division of Cardiothoracic Surgery, Medical College of Wisconsin, 9200 W. Wisconsin Ave, Milwaukee, WI 53226 (E-mail: halmassi@mcw.edu).

J Thorac Cardiovasc Surg 2006;131:502-3

$0022-5223 / \$ 32.00$

Copyright (C) 2006 by The American Association for Thoracic Surgery doi:10.1016/j.jtcvs.2005.09.043
}

earlier. One week later while she was at home, acute shortness of breath with wheezing developed. Results of a contrast computed

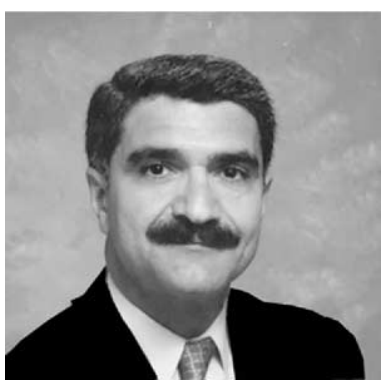

Dr H. Almassi tomographic (CT) scan of the chest were negative for pulmonary embolism. CT scan, however, revealed a $2.2-\mathrm{cm}$ round mass anterior to the superior vena cava and adjacent to the ascending aorta. There was no mediastinal lymphadenopathy (Figure 1, A). The patient was referred for further treatment. Review of the CT scans obtained at the time of the car crash demonstrated the presences of this mass, albeit, smaller (Figure 1, $B$ ).

The patient's chest was explored through a limited partial upper sternotomy incision. The mass was found to be an aneurysm of the right internal thoracic vein just before its connection to the innominate vein (Figure 2). The right internal thoracic vein was ligated on both sides of the aneurysm, and the mass was excised. The patient made an uneventful recovery. Pathologic examination was negative for malignancy.

\section{Discussion}

Anterior mediastinal masses may present a challenge in diagnosis. Depending on the age of the patient and symptoms, these may 

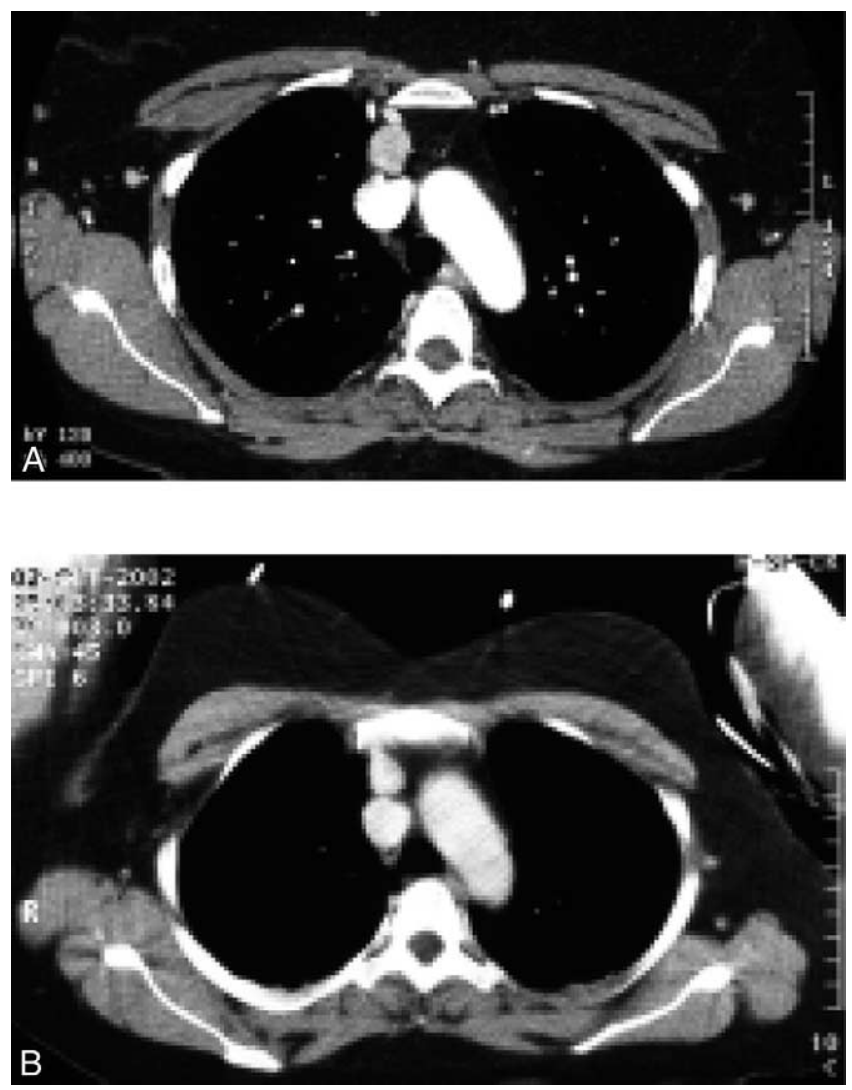

Figure 1. A, Right internal thoracic vein aneurysm at initial presentation. B, Right internal thoracic vein aneurysm 16 months earlier.

range from lymphomas to thymic tumors, substernal thyroid masses, or parathyroid adenomas. Aneurysmal dilatation of internal thoracic artery is uncommon but has been reported. ${ }^{1-5}$ In 2 reports, patients had connective tissue disorders. ${ }^{4,5}$ Isolated internal thoracic vein aneurysm presenting as an enlarging mass has not been reported before. In the differential diagnosis of anterior mediastinal masses this entity should be considered. Our patient did not exhibit any stigmata of a connective tissue disorder.

The cause of this aneurysm is not clear to us. Trauma may have played a role, but lack of any sternal or rib injury and mediastinal hematoma at the time of the patient's car crash argues against it. We did not suspect a connective tissue disorder in our patient.

Diagnosis of internal thoracic vein aneurysm can be established by contrast $\mathrm{CT}$ scan of the chest with image acquisition in the

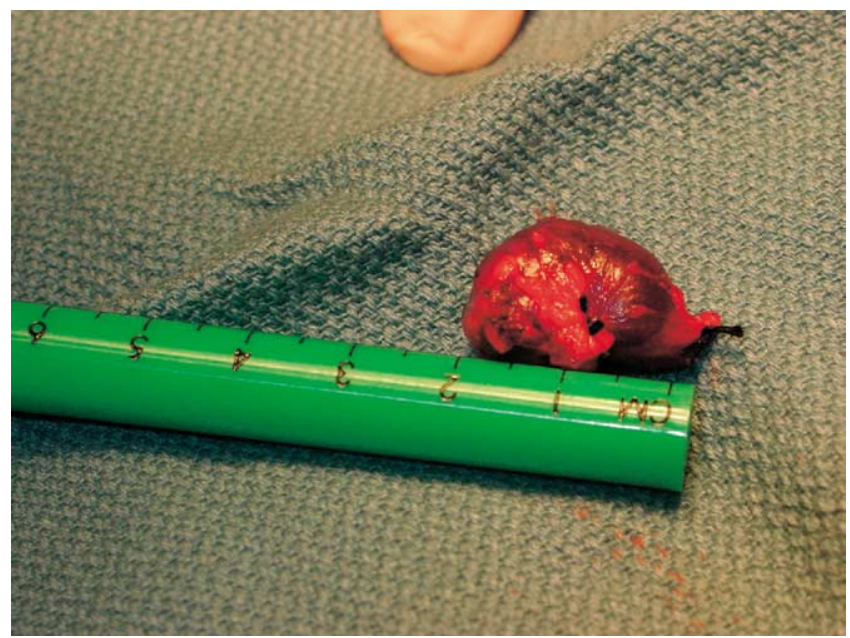

Figure 2. Internal thoracic vein aneurysm.

venous phase. With the new generation of multislice CT scanners, the diagnosis is easily established. Once diagnosed, treatment can be individualized. Small asymptomatic aneurysms should be observed. An enlarging aneurysm can be removed surgically.

An anterior mediastinotomy would have proven difficult for excision in our patient, although location further distal in the course of the internal thoracic vein may lend itself more easily to this approach.

Surgical excision of the internal thoracic vein aneurysm is done easily through an upper partial sternal split incision. A thoracoscopic approach would have been feasible but more difficult. The decision to remove the aneurysm in our patient was based on documented increase in the size over a 16-month period and the patient's desire and insistence that the mass be removed.

\section{References}

1. Otter GD, Stam J. Aneurysm of internal mammary artery. Thorax. 1978;33:526-7.

2. Wildhirt S, Eckel L, Beyersdorf F, Satter P. Atherosclerotic aneurysm of the right internal mammary artery presenting as a mediastinal mass. J Thorac Cardiovasc Surg. 1994;107:1535-6.

3. Giles JA, Sechtin AG, Waybill MM, Moser RP Jr. Bilateral internal mammary artery aneurysms: a previously unreported cause for an anterior mediastinal mass. Am J Roentgenol. 1990;154:1189-90.

4. Pressacco J, Wilson JK. Internal mammary artery aneurysm in Marfan syndrome: case report. Can Assoc Radiol J. 1999;5:47-50.

5. Phan TG, Sakulsaengprapha A, Wilson M, Wing R. Ruptured internal mammary artery aneurysm presenting as massive spontaneous haemothorax in a patient with Ehlers-Danlos syndrome. Aust N Z J Med. 1998;28:210-1. 